\title{
Editorial
}

Daniela Ottinger

Programmplanerin Ergotherapie

daniela.ottinger@thieme.de

\section{Auf dem richtigen Weg}

_ An manche Szenen in meiner Ergotherapieausbildung kann ich mich gut erinnern. Vor allem an den Kampf, wenn es darum ging, für Patienten Ziele zu formulieren: Ist „Verbesserung der Feinmotorik“ bei Kindern ein Grob- oder eher ein Feinziel? Welche therapeutischen Maßnahmen muss man ergreifen, um das identifizierte Ziel zu erreichen? Bei diesen Fragen schieden sich manchmal die Geister - und hatten die Dozenten eine andere Meinung als man selbst, kassierte man im schlimmsten Fall sogar eine schlechtere Note.

_ Elf Jahre ist es her, dass ich die Schulbank in der Berufsfachschule gedrückt habe. In dieser auf den ersten Blick kurzen Zeit hat sich viel verändert: Aus Patienten sind Klienten geworden. Wir „zwingen“ ihnen nicht mehr unsere therapeutischen Ziele auf, sondern hinterfragen, in welchen für sie wichtigen Betätigungen oder Alltagsaktivitäten sie Unterstützung brauchen. Und setzen dort mit unserer Therapie an. Aus meiner Sicht ist dieser Alltagsbezug ein wichtiger und für den Therapieerfolg elementarer Schritt.

_ Wie schwer es allerdings ist, die Ziele „neu“ zu formulieren, konnte ich kürzlich hautnah miterleben, als ich einen COPM-Kurs besuchte. Die Kursteilnehmer lernten zu hinterfragen, ob gewählte Ziele sinnvoll, messbar, akzeptabel oder realistisch sind. Klingt einfach, ist aber kniffliger, als man denkt. Vor allem, weil man schnell in die gewohnten Formulierungsmuster zurückfällt.

_ Der eingeschlagene Weg ist richtig - weg von rein funktionsorientierten Zielen hin zu Therapiezielen, die für unsere Klienten wirklich alltagsrelevant sind. Auch wenn es uns dann manchmal erstaunen wird, dass es für ein Kind wichtiger ist, im neuen Schuljahr Freunde zu finden, anstatt mit uns an der „Verbesserung der Feinmotorik“ zu arbeiten. Den Weg konsequent zu gehen, erfordert von uns sicherlich jede Menge Mut. Ich bin jedoch überzeugt, dass sich das Umdenken lohnt. Dies zeigen auch die positiven Beispiele in dieser ergopraxis-Ausgabe (॰ Seite 8 und 28).

Herzlichst

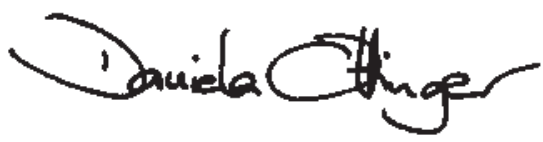

PS: Im Namen der gesamten Redaktion wünsche ich Ihnen eine entspannte Vorweihnachtszeit, geruhsame Weihnachten und einen energiegeladenen Rutsch ins neue Jahr!

\section{ZU GEWINNEN}

Kursplatz

1 Kurs „Narbenbehandlung“Seite 43

Bücher

3-mal

„Stolpersteine - na und?“ Seite 22

3-mal „Ergotherapie

bei Kindern mit

Koordinationsstörungen“ Seite 51

3-mal „Ist mein Kind

hochbegabt?"

Seite 51

Und außerdem...

2 Kumquats (Handpuppen) Seite 17

2 Dauerkalender aus Holz Seite 51

2 winterliche Pflegesets Seite 51 